\title{
Urgensi Pengaturan Keamanan Maritim Nasional di Indonesia
}

\author{
Dhiana Puspitawati, Kristiyanto
}

DATA NASKAH

Masuk: 2 Februari 2017

Diterima: 24 Maret 2017

Terbit: 1 Juni 2017

KORESPONDEN PENULIS:

Fakultas Hukum Universitas Brawijaya JI. MT. Haryono 169 Malang 65145, Telp. (0341) 553898 Fax. (0341) 566505

E-mail:dhiana@ub.ac.id

\section{ABSTRACT}

Located between two continents and two oceans, Indonesia is vulnerable to various transnational crimes. Hence, the concept of maritime security emerged. This paper focuses on three crucial matters, maritime delimitation, IUU Fishing as well as piracy and armed robbery at sea. This research aims to analyze the urgency of national maritime security legal framework in Indonesia. This research uses normative method with statute approach and comparative approach. It is submitted that although regional dan international cooperation is important to address maritime threats, national legal instrument is also necessary. Unfortunately, Indonesia still does not have comprehensive national legal instrument in place. Thus, it is argued that Indonesia should formulate specific policy and national legal frameworks in addressing maritime threats completed with certain measures for each threats as well as point out which institutions competent in handling each threats.

Keywords: Maritime Security, Sovereignty, IUU Fishing, Piracy, Armed Robbery at sea

\section{ABSTRAK}

Penelitian ini memfokuskan pada kajian urgensi pengaturan keamanan maritim nasional di Indonesia, yang memfokuskan pada tiga hal, yaitu perbatasan wilayah laut, IUU Fishing, serta perbuatan perompakan dan kekerasan bersenjata di laut. Penelitian ini bertujuan menganalisa urgensi penetapan kerangka hukum nasional dalam keamanan maritime, dan metode yang digunakan adalah normatif dengan pendekatan perundangundangan serta studi komparasi. Hasil studi yang telah dilakukan yaitu: meskipun kerjasama internasional dan regional sangat penting dalam keamanan maritim, ketersediaan instrumen hukum nasional tentang keamanan maritim sangat diperlukan. Sayangnya, Indonesia belum memiliki instrumen hukum tersebut. Oleh karena itu, disarankan agar 
Indonesia merumuskan intrumen hukum yang mengatur akan ancaman maritim dengan mekanisme penanganan masing-masing dan institusi penegak hukum masing-masing.

Keywords: Keamanan Maritim, Kedaulatan, IUU Fishing, Perompakan, Kekerasan Bersenjata di laut

\section{PENDAHULUAN}

Pada era globalisasi, meskipun paperless transaction lebih disukai, proses perdagangan internasional tetap membutuhkan pengiriman barang ke tempat tujuan (Dhiana dan Nurdin, 2014:239). Walaupun tersedia setidaknya enam macam moda transportasi dalam mendukung terselenggaranya perdagangan internasional, transportasi laut masih menjadi pilihan utama para pelaku perdagangan internasional. Berdasarkan time utility dan cost utility transportasi laut menjanjikan kapasitas dan kualitas yang tinggi. Walaupun biaya tetap (fix cost) cukup tinggi, biaya ikutan (variable cost) sangatlah rendah. Hal inilah yang menyebabkan $90 \%$ perdagangan internasional dilaksanakan melalui laut dengan menggunakan kapal sebagai alat pengangkutan barang. Meskipun demikian, dari sudut pandang keamanan, lingkungan maritim sangatlah rentan akan tindakan kejahatan terutama kejatahan lintas negara (transnational crime). Dari sinilah muncul konsep keamanan maritim atau biasa dikenal dengan maritime security.

Meskipun belum ada definisi universal tentang keamanan maritim, konsep keamanan maritim masih terus berkembang mencari bentuknya baik di ranah internasional maupun nasional (Keliat, 2009:2). Bautista mengatakan bahwa pengertian sempit maritime security mencakup perlindungan terhadap integritas wilayah suatu negara (Bautista, 2013). Dalam perkembangannya, maritime security meliputi ancaman maritim yang mencakup traditional maritime security, seperti: bajak laut (piracy) dan perampokan bersenjata di laut (armed robbery at sea), peredaran obat-obat terlarang (drug trafficking) (Bateman, 2006:28), perdagangan manusia (people smuggling) (Andreas Schloenhardt, 2003); terorisme (Bateman, 2006:77), dan kejahatan lintas negara lainnya. Maritime security terus berkembang dan mencakup juga ancaman terhadap lingkungan laut dalam kaitannya dengan polusi laut, baik polusi yang berasal dari aktifitas di daratan maupun polusi akibat pengoperasian kapal (David, 2006), meningkatnya lalu lintas pelayaran (Joon, 2003:61), illegal unreported unregulated (IUU) fishing (OECD, 2004), dan juga perubahan iklim (climate change) (Melinda, 2007:1).

Letak geografis Indonesia pada posisi silang, yaitu antara dua benua, Australia dan Asia serta antara dua samudra, Hindia dan Pasifik membuat perairan Indonesia sebagai pusat pelayaran internasional dalam rangka perdagangan internasional dan juga menjadikan perairan Indonesia rentan akan berbagai macam ancaman keamanan sebagaimana disebutkan di atas. Dengan demikian sangat diperlukan pengaturan hukum dalam menghadapi berbagai ancaman keamanan maritim. Akan tetapi, tidak semua negara mempunyai kerangka hukum secara nasional yang spesifik mengatur tentang ancaman terhadap keamanan maritim ini. Indonesia belum mempunyai kerangka hukum/ aturan hukum nasional yang secara spesifik mengatur penegakan hukum terhadap ancaman maritim yang menyeluruh, baik secara susbstansi maupun mekanisme. Hal ini berbeda dengan Australia yang sudah mempunyai kerangka hukum/ aturan hukum nasional yang secara spesifik mengatur penegakan hukum terhadap ancaman maritim yang menyeluruh, yang biasa dikenal dengan GAMSA (Guide to Australian Maritime Security Arrangement). Selama melakukan penegakan hukum di laut, Indonesia (dalam hal ini TNI-AL) hanya berpegang pada Peraturan KSAL No. 32 Tahun 2009 tentang Prosedur Tetap Penegakan Hukum dan Penjagaan Keamanan di Wilayah Laut Yurisdiksi Nasional oleh TNI-AL (PerKSAL No 32 Tahun 2009). Tentunya ketentuan semacam ini hanya berlaku sebagai pegangan intern TNI-AL saja.

Untuk itu, penelitian ini fokus pada urgensi pengaturan keamanan maritim secara nasional (maritime security arrangement) dan mengusulkan bentuk aturan hukum yang sesuai dengan Indonesia guna menghadapi ancaman terhadap keamanan maritim. Dari uraian sebagaimana dikemukakan pada latar belakang di atas, maka rumusan masalah dalam penelitian ini adalah: (1) apa urgensi pengaturan keamanan maritim nasional (national maritime security arrangement) di Indonesia?, dan (2) apakah instrument hukum tentang keamanan maritime di Indonesia sudah cukup memadai untuk menghadapi ancaman maritime yang ada?. 


\section{METODE PENELITIAN}

Metode yang digunakan adalah metode normatif dengan pendekatan perundang-undangan dan studi komparasi. Inisiasi-inisiasi serta kerjasama-kerjasama yang sudah dilakukan Indonesia baik internasional maupun regional dalam menghadapi berbagai ancaman maritim dan akibat hukumnya terhadap keamanan maritim di Indonesia akan dianalisa. Selanjutnya, penelitian ini akan mengadakan studi komparasi dengan Australia, sebagai negara pantai terdekat yang sudah mempunyai aturan secara nasional yang secara spesifik mengatur tentang keamanan maritim.

\section{HASIL PENELITIAN DAN ANALISIS}

\section{A. Urgensi Pengaturan Keamanan Maritim}

Keamanan maritim mencakup berbagai tindakan yang bervariasi yang meliputi baik kejahatan maupun kegiatan ilegal yang dilakukan di laut sampai permasalahan mengenai sengketa batas wilayah laut. Keamanan maritim (maritime security) acapkali dianggap sebagai konsep yang tidak definitif. Dalam perkembangannya, keamanan maritim meliputi berbagai sektor, baik sektor publik, privat, nasional, internasional guna tercapainya ketertiban di laut. Meskipun tidak ada keseragaman dalam mendefinisikan keamanan maritim, sebagaimana dijelaskan sebelumnya, keamanan maritim (CSDP, 2010) harus dibedakan dari keselamatan maritim. Tercapainya keamanan maritim dan keselamatan maritim akan mewujudkan suatu kesiagapan maritim yang baik yang biasa disebut dengan Maritime Domain Awareness. Goward selanjutnya menggambarkan suatu tabel untuk menunjukkan aspek-aspek apa sajakah yang harus ada untuk mewujudkan Maritime Domain Awareness (MDA) yang baik sebagai berikut (Goward, 2006):

Selanjutnya Wibawa (2016) mengatakan setidaknya ada 3 isu utama dalam keamanan maritim, yaitu permasalahan perbatasan wilayah laut, Illegal, Unregulated and Unreported Fishing (IUU Fishing) serta pembajakan dan tindak kekerasaan di laut (piracy and armed robbery at sea). Dengan ketidakjelasan perbatasan wilayah laut, maka dalam pelaksanaannya akan terjadi insiden IUU Fishing karena tidak jelasnya wilayah laut tersebut merupakan wilayah laut negara mana. Sementara itu, piracy dan armed robbery at sea merupakan tindak kejahatan yang sudah ada sejak lama di wilayah laut. Keamanan maritim yang dimaksud dalam penelitian ini hanya fokus pada tiga hal tersebut, yakni perbatasan wilayah laut, IUU Fishing serta pembajakan dan tindakan kekerasan di laut.

Tabel 1.

Aspek-aspek yang harus diperhatikan untuk mewujudkan MDA

\begin{tabular}{ll}
\hline Keselamatan & - Keselamatan Maritim \\
& - Search and Rescue \\
\hline Keamanan & - Kesiapan pertahanan \\
& - Keamanan Pelabuhan, Alur laut dan \\
& Pesisir \\
& Larangan perdagangan obat \\
& terlarang \\
& - Larangan illegal migration \\
& - Penegakan Hukum yang lainnya \\
\hline Stewardship & Perlindungan Lingkungan Laut \\
& - Perlindungan sumber daya kelautan \\
& - Rambu-rambu Navigasi \\
& Ice Operations \\
\hline Sumber: D.A. Goward, Maritime Domain Awareness Integration \\
Challenges, SLAAD 2008
\end{tabular}

1. Isu Keamanan Maritim di Perairan Indonesia

Indonesia sebagai negara kepulauan terbesar berbatasan wilayah laut dengan 10 negara tetangga, yaitu Malaysia, Singapore, Thailand, Vietnam, Filipina, Timor Leste, Australia, India, Palau dan Papua Nugini. Dengan demikian, untuk menghadapi ancaman maritim yang ada perbatasan wilayah laut yang jelas sangat penting. Meskipun beberapa perbatasan wilayah laut sudah diselesaikan, masih banyak juga perbatasan wilayah laut yang belum disepakati, yang menyebabkan terjadinya insiden-insiden IUU Fishing karena perbedaan persepsi atas wilayah laut, terutama di wilayah perbatasan laut antara Indonesia dan Malaysia serta Indonesia dan Singapura.

Masih adanya perbatasan laut yang belum disepakati, menimbulkan rawan konflik dengan negara yang berbatasan, kejahatan internasional merupakan salah satu ancaman bagi Indonesia. Perbatasan wiayah laut antara Indonesia dan negara tetangga pada umumnya saling bersinggungan di ZEE dan landas kontinen. Batas wilayah laut yang sudah selesai dilakukan dan disepakati di semua segmen hanya batas wilayah laut antara Indonesia dan Singapura serta dengan Papua Nugini. Sementara batas wilayah laut, dalam hal ini batas ZEE dan landas kontinen antara Indonesia dengan Malaysia, Filipina, India, Thailand, Vietnam dan Palau 
belum ada selesai. Meskipun beberapa perundingan sudah dilakukan dan sudah disepakati di beberapa titik, sementara dengan Australia juga telah dilakukan perjanjian batas wilayah laut lengkap dengan perjanjian kerjasama baik dalam hal kedaulatan dan pengelolaan sumber daya laut. Sedangkan dengan Timor Leste akan dimulai perundingan batas wilayah laut dengan segera, mengingat sebelumnya hanya dilakukan perjanjian pada batas wilayah darat.

Dengan demikian sudah tentu perairan di daerah perbatasan yang masih belum disepakati akan berpotensi terhadap munculnya berbagai ancaman maritime seperti IUU Fishing, Illegal logging, Smuggling, Human Trafficking dan sejenisnya. Garis batas yang belum disepakati juga akan mengakibatkan keragu-raguan bagi penegak hukum di laut dalam upaya penegakan hukum di laut. Belum adanya kesepakatan pada titik-titik wilayah perbatasan laut tertentu inilah yang menyebabkan banyak insiden IUU Fishing. Pada tahun 2014 tercatat lebih dari 100 kapal ikan asing yang melakukan IUU Fishing di Indonesia yang menyebabkan kerugian Indonesia sekitar 24 milyar Dollar (Steve, "Indonesia Declares War on Illegal Foreign Fishing Vessels", diakses di < http:// www.voanews.com/content/indonesia-declares-war-on-illegal-foreign-fishing-vessels/2570346.html>, pada14 July 2016).

Selanjutnya, tentang pembajakan dan kekerasan di laut atau piracy and armed robbery at sea, kawasan perairan di Asia Tenggara menduduki peringkat kedua di dunia untuk kawasan paling rawan pembajakan dalam kurun waktu 2008-2012 (ICC IMB, 2012). Sementara itu, di antara negaranegara di Asia Tenggara, perairan Indonesia merupakan perairan paling berbahaya dikarenakan angka terjadinya piracy and armed robbery at sea paling tinggi ditemukan di perairan Indonesia, terutama di Selat Malaka. Angka ini semakin hari semakin meningkat dan perairan Indonesia tetap menempati peringkat pertama. Data yang diambil pada tahun 2015 malah menunjukkan perairan Indonesia yang menduduki peringkat pertama dalam kawasan paling rawan piracy dan armed robbery at sea, mengalahkan Nigeria. Meskipun keamanan maritim pada umumnya memerlukan kerjasama regional maupun internasional, namun tersedianya hukum nasional juga diperlukan terutama dalam mendukung upaya penegakan hukum terhadap ancaman-ancaman maritim yang ada. Sebelum menganalisa kerangka hukum nasional, kerjasama regional yang sudah ada akan dianalisa terlebih dahulu.

\section{Respon secara Regional dan Nasional}

Pada tingkat regional, sudah banyak dilakukan kerjasamakerjasama dalam penanggulangan terhadap semua ancaman maritim yang terjadi (Johnson, 2005: 202). Sebenarnya kerjasama regional yang dilakukan tidak melulu karena kedekatan letak geografis negara akan tetapi lebih kepada fungsi dari kerjasama tersebut. Hal ini dapat dilihat dari pengaturan secara regional yang disebut Regional Cooperation Agreement against Piracy and Armed Robbery (ReCAAP) yang dimotori oleh AS, Jepang dan Singapore sebagai satu instrumen dalam mencegah dan menekan pembajakan dan perampokan bersenjata di Asia, sayangnya Malaysia dan Indonesia tidak turut serta dalam perjanjian tersebut.

Sebagai organisasi regional di kawasan Asia Tenggara, ASEAN tidak tinggal diam akan ancaman maritim yang terjadi di perairan Asia Tenggara. ASEAN telah membentuk beberapa forum diantaranya ASEAN Maritime Forum (AMF), ASEAN Regional Forum Inter-Sessional Meeting (ARF-ISM) on Maritime Security dan Maritime Security Expert Working Group (MSEWG) (Bateman, 2013:16). Sayangnya mekanisme yang dimiliki ASEAN belum sampai pada implementasi di lapangan dalam mencegah dan menanggulangi ancaman terhadap keamanan maritim, akan tetapi masih dalam tataran dialog kebijakan dan norma berupa seminar-seminar serta workshop dan roundtable meeting saja. Upaya-upaya tersebut masih dalam batasan dialog kebijakan dan perumusan-perumusan kerjasama lanjutan.

Keliat (2009) mengatakan bahwa sulitnya implementasi kerjasama tersebut dalam tataran operasional adalah enggannya suatu negara melibatkan pihak luar dalam melakukan pengamanan wilayah lautnya. Hal ini mengingat adanya prinsip kedaulatan negara yang absolut dan eksklusif. Meskipun demikian, sebenarnya mekanisme yang dilakukan ASEAN cakupannya lebih luas daripada konsep maritime security yang dirumuskan oleh PBB. Hal ini dikarenakan konsep maritime security yang dirumuskan oleh ASEAN sudah mencakup lingkungan laut dan kegiatan penangkapan 


\section{MEDIA
HUKUM}

ikan illegal. Sayangnya apa yang dihasilkan ARF tidak mengikat hanya pada tataran kebijakan yang mengutamakan Community Based Management yang kurang efektif untuk tataran operasional.

Selanjutnya, secara nasional, upaya Indonesia dalam menanggulangi /UU Fishing adalah dikeluarkannya kebijakan 'penenggelaman kapal' yang terlibat dalam IUU Fishing khususnya untuk kapal berbendera asing (Jokowi, "Tenggelamkan Kapal Pencuri lkan!", < http://nasional.kompas.com/ read/2014/11/18/13004411/Jokowi. Tenggelamkan.Kapal.Pencuri.Ikan>, diakses pada 14 Juli 2016). Kebijakan penenggelaman kapal tersebut dituangkan dalam UndangUndang No. 45 Tahun 2009 tentang Perikanan, namun kebijakan ini tentu saja bertentangan dengan ketentuan UNCLOS 1982.

Sementara itu, dalam hal menanggulangi piracy and armed robbery at sea Indonesia belum melakukan upaya untuk membentuk hukum nasional maupun menyesuaikan hukum nasional yang sudah ada dengan ketentuanketentuan internasional yang ada. Selain UNCLOS 1982 instrumen Hukum Internasional yang mengatur piracy and armed robbery at sea lainnya adalah Convention for the Suppresion of Unlawful Acts against the Safety of Maritime Navigation (Konvensi SUA) tahun 1988 dan protokolnya. Konvensi ini merupakan salah satu instrumen hukum yang digunakan untuk memerangi tindakan-tindakan ilegal yang dilakukan di laut termasuk pembajakan terhadap kapal. Berbeda dengan Pasal 101 UNCLOS 1982, Konvensi SUA ini tidak mempertimbangkan motif dibalik tindakan pembajakan yang dilakuan (Supriyanto, 2012:28). Tidak seperti pengaturan dalam UNCLOS 1982 yang mensyaratkan adanya dua kapal serta harus terjadi di laut bebas untuk ruang lingkup tindakan pembajakan, Konvensi SUA berlaku pula pada serangan yang dilakukan di kapal yang mana kapal tersebut berlayar atau dijadwalkan berlayar menuju, melalui atau dari perairan diluar batas laut teritorial dari negara pantai; atau berlaku ketika pelaku penyerangan/yang diduga sebagai pelaku ditemukan di dalam wilayah dari negara peserta.

Pasal 10 ayat (1) Konvensi SUA menguraikan bahwa negara bertanggung jawab untuk mengadili atau mengekstradisi pelaku yang melakukan salah satu atau lebih dari kejahatan yang tercantum dalam pasal 3 Konvensi ini. Lebih lanjut, Pasal 11 ayat (1) Konvensi SUA menjelaskan bahwa dalam Pasal 3 yang dapat di ekstradisi berdasarkan perjanjian ekstradisi antara negara-negara. Pada kasus negara yang tidak memiliki perjanjian ekstradisi, maka konvensi melalui Pasal 11 ayat (2) memungkinkan negara untuk menggunakan Konvensi SUA sebagai dasar hukum ekstradisi (Harrelson, 2010:313). Sayangnya, negara-negara di kawasan Asia Tenggara masih banyak yang belum meratifikasi konvensi dan protokol tambahan dari The SUA Convention ini. Indonesia, Malaysia dan Thailand yang merupakan negara dimana perairan yurisdiksinya banyak terjadi kasus pembajakan dengan jumlah yang cukup signifikan.

\section{B. Ketentuan Hukum Nasional tentang}

\section{Keamanan Maritim}

\section{Keamanan Maritim di Indonesia}

Sebagaimana disebutkan di atas bahwa belum disepakatinya beberapa wilayah laut sebagai perbatasan wilayah laut antara Indonesia dan negara-negara tetangga dapat menimbulkan konflik serta semakin rentannya perairan Indonesia akan ancaman maritim seperti IUU Fishing serta piracy and armed robbery at sea. Ketidakpastian perbatasan wilayah laut juga merupakan salah satu sebab sulitnya penegakan hukum yang dilakukan apabila terjadi insideninsiden yang terkait dengan perbatasan wilayah laut. Meskipun demikian, bukan berarti Indonesia tidak berpegang pada suatu peta resmi dalam penegakan hukum di laut. Untuk wilayah laut yang belum disepakati, maka masingmasing pihak akan mengeluarkan peta klaim sepihak terhadap wilayah tersebut dan secara bersama-sama melakukan joint-patro/ di wilayah tersebut. Tentu saja akan terjadi banyak konflik terutama di wilayah yang belum disepakati, terutama jika menyangkut pemanfaatan sumber daya laut.

Selanjutnya, dalam masalah pemanfaatan wilayah laut di ZEE Bab V UNCLOS 1982 menayatakan bahwa negara pantai diberi hak berdaulat untuk eksplorasi dan eksploitasi sumber daya alam. Negara pantai diperbolehkan untuk membuat aturan hukum sendiri dan dapat diberlakukan di ZEE, khusus tentang eksplorasi dan eksploitasi sumber daya 
alam. Inilah yang disebut dengan hak berdaulat negara pantai di ZEE, yaitu hak eksklusif negara untuk memberlakukan hukumnya dalam bidang tertentu di wilayah yang bukan wilayah kedaulatannya. Pasal 73 UNCLOS 1982 juga memberikan hak kepada negara pantai dalam penegakan hukum terhadap pelanggaran yang dilakukan negara lain di ZEE, yang meliputi melakukan pemeriksaan kapal yang dicurigai dengan cara menaiki kapal dan memeriksa dokumen kelengkapan kapal serta melakukan penangkapan, jika diperlukan. Meskipun demikian, terdapat batasan terhadap penegakan hukum yang dilakukan Negara pantai, yaitu tidak mengenakan hukuman penahanan ataupun hukuman badan lainnya terhadap pelaku (UNCLOS, 1982). Pasal 73 UNCLOS 1982 mengatur bahwa terhadap pelnggaran yang terjadi di ZEE negara pantai tidak boleh mengenakan suatu 'corporal punishment' atau hukuman badan terhadap pelaku pelanggaran. Dalam hal ini, meskipun tidak diatur siapa yang disebut pelaku pelanggaran, penenggelaman kapal tetap bisa dikatakan sebagai hukuman badan atau 'corporal punishment'.

Dalam pengaturan hukum nasional, permasalahan perikanan di atur dalam Undang-Undang No.45 Tahun 2009 (UU No. 45/ 2009). Dalam salah satu ketentuannya yaitu Pasal 69 UU No.45/2009 dikatakan bahwa pihak yang berwenang dapat melakukan penelnggelaman kapal atas kapal yang sudah terbukti melakukan IUU Fishing. Selanjutnya Pasal 76 (A) UU No. 45/ 2009 menyebutkan bahwa penenggelaman kapal dapat dilakukan sesudah ada penetapan atau persetujuan pengadilan. Meskipun terdapat dasar hukum dalam penenggelaman kapal, akan tetapi hal ini harus dilihat kesesuaiannya dengan ketentuan UNCLOS 1982. Meskipun UNCLOS memberikan hak kepada negara pantai untuk merumuskan dan memberlakukan hukumnya sendiri dalam hal eksplorasi dan eksploitasi sumber daya alam, Pasal 73 UNCLOS 1982 dengan jelas mengatakan bahwa hukuman yang diberikan kepada pelaku pelanggaran di ZEE tidak boleh berupa penahanan atau hukuman badan lainnya.

Pembakaran kapal sebagai hukuman dapat dikatakan merupakan hukuman badan, kapal dalam hal ini bukan saja berfungsi sebagai alat bukti belaka. Sayangnya, tidak ada ketentuan secara eksplisit siapa yang disebut sebagai pelaku dalam pelanggaran yang dilakukan di ZEE, apakah para nelayan yang melakukan IUU Fishing atau kapal yang digunakan, mengingat dalam hukum maritim kapal dianggap sebagai subyek hukum (Bjunme dan Catherine, 2007), karena pada dasarnya hukum maritim mengatur segala sesuatu yang berhubungan dengan kapal dan pengoperasiannya. Hukum maritim merupakan hukum yang fokus utamanya adalah kapal. Dengan demikian, sangat penting jikalau Indonesia harus memikirkan kembali tentang kesesuaian UU No. 45/ 2009 dengan ketentuan dalam UNCLOS 1982 terutama ketentuan mengenai ZEE.

Selanjutnya, dalam hal piracy and armed robbery at sea satu-satunya peraturan perundangan tentang pembajakan dapat ditemukan dalam hukum Pidana Indonesia yaitu dalam Kitab Undang-Undang Hokum Pidana (KUHP). Akan tetapi ketentuan tentang pembajakan yang diatur dalam KUHP sudah tidak sesuai lagi. KUHP merupakan produk peninggalan pemerintah Belanda yang berlaku berdasarkan asas konkordansi. Saat ini ketentuan Belanda yang dituangkan dalam KUHP sudah tidak berlaku lagi di Belanda, sementara itu ketentuan-ketentuan dalam KUHP masih tetap berlaku di Indonesia. Ketentuan masalah pembajakan diatur dalam Bab XXIX KUHP yang dikategorikan sebagai kejahatan pelayaran. Disamping itu, ketentuan tentang pembajakan yang diatur dalam KUHP tidak sesuai dengan definisi pembajakan atau piracy yang diatur dalam UNCLOS 1982. Pasal 101 UNCLOS 1982 secara eksplisit menyebutkan bahwa tindakan piracy adalah tindakan kekerasan yang dilakukan di laut bebas, bukan berarti tindakan tersebut bebas dari hukum. Hal ini diatur dalam Pasal 105 UNCLOS 1982 tentang diberlakukannya asas jurisdiksi universal terhadap piracy, sehingga semua Negara bisa menegakkan jurisdiksinya atas piracy. Sebaliknya, Pasal 438 KUHP mengatur bahwa pembajakan atau tindakan bajak laut adalah tindakan kekerasan yang dilakukan di wilayah perairan Indonesia dan bukan di laut bebas.

Selanjutnya Pasal 439 dan 440 KUHP mengatur tentang locus delicti piracy dan armed robbery at sea. Menurut KUHP piracy dan armed robbery at sea merupakan kejahatan yang dilakukan di perairan pedalaman, seperti sungai serta perairan Indonesia. Selanjutnya menurut KUHP yang dimaksud dengan perairan Indonesia adalah perairan Indo- 


\section{MEDIA
HUKUM}

nesia sebagaimana dimaksud oleh Territorial zee en Maritieme Kringen Ordonantie 1939 (TZMKO 1939), yang hanya memberikan negara pantai laut territorial seluas 3 mil laut saja. Sementara itu, sejak Indonesia merdeka TZMKO 1939 sudah dinyatakan tidak berlaku lagi dan diganti dengan UU No.4/Prp/ 1960 tentang perairan Indonesia dan yang sudah diganti lagi dengan UU No. 6 Tahun 1996 tentang hal yang sama. UU No. 6 Tahun 1996 telah mengadopsi zona-zona maritim yang diatur dalam UNCLOS 1982, yang mana suatu negara pantai diberikan hak beberapa zona maritim dengan kewenangannya masing-masing. Dengan demikian, aturan KUHP tentang pembajakan di laut sudah tidak relevan lagi dengan perkembangan jaman dan dengan demikian bisa dikatakan hal tersebut tidak dapat berlaku lagi. Dengan kata lain, Indonesia tidak dapat mengadili pelaku piracy maupun armed robbery at sea karena memang tidak ada hukum nasional untuk itu. KUHP Bab XXIX tidak dapat dijadikan dasar hukum dalam memeriksa perkara piracy dan armed robbery at sea.

Ketentuan hukum lainnya yang relevan dengan masalah tersebut adalah UU No. 17 Tahun 2008 tentang Pelayaran. Undang-undang ini dikatakan sebagai Indonesian Maritime Act, namun UU No. 17/ 2008 tidak mengatur tentang keamanan maritim dan tidakjuga mengatur tentang pembajakan dan tindakan kekerasan di laut. Dengan demikian bisa dikatakan bahwa secara nasional Indonesia tidak mempunyai kerangka hukum yang spesifik tentang keamanan maritim, yang mencakup semua ancaman maritim yang ada. Meskipun demikian, bukan berarti Indonesia tidak melakukan apapun untuk menghadapi ancaman maritim, khususnya piracy. Disamping aktif dalam kerjasama regional maupun internasional dalam menghadapi ancaman maritime, Indonesia mempunyai aturan teknis tentang bagaimana menghadapi ancaman maritim, yaitu Peraturan KSAL Nomor PerKSAL/32N/2009 tanggal 4 Mei 2009 tentang Prosedur Tetap Penegakan Hukum dan Penjagaan Keamanan di Wilayah Laut Yurisdiksi Nasional oleh TNI AL. PerKSAL ini dibuat sebagai peraturan pelaksana dari PAsal 9 UU No. 34 Tahun 2004 tentang Tentara Nasional Indonesia. Namun, PerKSAL ini hanya merupakan pedoman teknis bagi TNI-AL (KSAL, 2009) dalam melakukan penegakan hukum di laut dan tidak bisa dikatakan sebagai kebijakan nasional maupun ketentuan hukum Indonesia tentang keamanan maritim. Disamping itu, PerKSAL ini hanya digunakan oleh TNI-AL, padahal institusi penegak hukum di laut bukan hanya TNI$A L$, dan PerKSAL ini tidak dapat digunakan oleh institusi penegak hukum di laut non TNI-AL.

\section{Perbandingan dengan Australia}

Guna memperoleh gambaran akan kerangka hukum yang komprehensif untuk keamanan maritim yang mencakup semua jenis ancaman maritim, maka studi perbandingan harus dilakukan. Dalam hal ini perbandingan dilakukan dengan melihat kerangka hukum yang dimiliki oleh Australia. Hal ini disebabkan karena Australia merupakan negara terdekat dari Indonesia yang sudah mempunyai kerangka hukum yang komprehensif yang mencakup semua jenis ancaman maritim dalam suatu dokumen yang disebut Guide to Australian Security Arrangement (GAMSA). GAMSA merupakan dokumen multi-egency yang berfungi sebagai kerangka keamanan maritime Australia. Dokumen ini mengatur secara detail tentag berbagai jenis ancaman maritim lengkap dengan masing-masing institusi penegak hukumnya untuk jenis ancaman maritime yang berbeda. Misalnya, institusi yang mempunyai kewenangan untuk mengatsai IUU Fishing akan berbeda dengan institusi yang akan menangani pembajakan di laut, pengaturan semacam ini tidak ditemukan di Indonesia.

GAMSA memisahkan antara institusi primer dan sekunder. Institusi primer bertanggungjawab dalam mengatur terhadap ancaman maritime tertentu, sedangkan institusi sekunder bertanggungjawab memberikan nasehat/ kebijakan terhadap ancaman maritim yang ada. Tiap Bab dalam GAMSA mengatur dengan detail masing-masing ancaman maritim lengkap dengan institusi mana yang bertanggung jawab. Tidak seperti PerKSAL, GAMSA dapat diterapkan secara nasional, bukan hanya digunakan dikalangan Angkatan Laut saja. Dengan demikian ada keseragaman dalam menghadapi ancaman maritim guna menegakkan keamanan maritim, tanpa adanya tumpang tindih kewenangan, khususnya dalam penegakan hukum di laut. Model seperti inilah yang seharusnya di adopsi oleh Indonesia sehingga ada keseragaman dalam menghadapi ancaman maritim dan dalam melakukan penegakan hukum di laut. 
GAMSA juga mengatur secara detail para stakeholder terkait dengan pengamanan-pengamanan maritim yang harus dilakukan dan peran apa yang bisa mereka lakukan dalam menghadapi berbagai ancaman maritim yang ada. Disamping itu, mekanisme teknis penegakan hukum, GAMSA juga mengatur aspek administrasi dan hukum dari masing-masing ancaman maritim yang timbul. Dalam GAMSA juga diuraikan kerjasama apa yang sudah dilakukan Australia baik secara internasional maupun nasional dalam mengatasi ancaman maritime dan bagaimana hukum nasionalnya harus menyesuaiakn dengan kesepakatankesepakatan yang sudah dibuat oleh Australia dengan negara lain. Dalam GAMSA juga dirumuskan definisi maupun ruang lingkup dari masing-masing ancaman maritim sehingga dalam penegakan hukumnya secara nasional sudah ada kesamaan persepsi seluruh pihak yang berwenang dalam penegakan hukum akan suatu tindakan ancaman maritime tertentu. Daerah-daerah dimana merupakan Marine Protected Areas (MPA) juga diurutkan secara sitematik lengkap dengan mekanisme perlindungan dan pengawasannya serta institusi yang bertanggungjawab, demikian juga dengan masing-masing ancaman maritim yang ada.

Hal yang dapat diambil untuk diterpakan di Indonesia adalah model pengaturan institusi yang berwenang dalam penanganan ancaman maritim. Dipisahkannya antara institusi primer dan sekunder mungkin bisa mengantisipasi tumpang tindihnya kewenangan dalam penegakan hukum, khususnya penegakan hukum di laut. Meskipun Indonesia telah mempunyai Badan Keamanan Laut Republik Indonesia (Bakamla) akan tetapi mekanisme kerja dari Bakamla dan institusi penegak hukum lainnya belum terintegrasi sehingga menyebabkan kesulitan dalam praktek di lapangan. Model dari GAMSA dapat diadopsi Indonesia sehingga Indonesia mempunyai legal framework yang dapat diberlakukan dan dapat dijadikan pegangan bagi semua instansi penegak hukum di laut bukan hanya Angkatan Laut saja.

Definisi dan ruang lingkup dari setiap ancaman maritim yang ada juga harus dituangkan dalam bentuk kerangka hukum yang terintegrasi sehingga tidak terjadi perbedaan intepretasi dalam menentukan suatu ancaman maritim. Dengan adanya kerangka hukum yang terintegrasi lengkap dengan institusi yang berwenang, penegakan hukum akan berbagai ancaman maritime akan dapat mudah dilakukan oleh seluruh penegak hukum di laut.

Selanjutnya, bervariasinya ancaman maritim yang ada mendorong suatu negara untuk mempunyai suatu pengaturan yang komprehensif dan multy-agency tentang mekanisme menghadapi ancaman maritim dalam suatu kerangka hukum. Indonesia dapat mengadopsi praktek yang dilakukan oleh Australia yang telah memiliki legal framework yang baik dalam mengatur keamanan maritim negaranya. Sehingga sudah saatnya Indonesia merumuskan ketentuan hukum nasional yang mengatur tentang semua ancaman maritime dalam suatu ketentuan hukum yang komprehensif. Revisi terhadap ketentuan hukum yang ada yang relevan dengan keamanan maritim juga harus dilakukan, baik menyesuaikannya dengan ketentuan internasional maupun menyesuaikannya dengan perkembangan hukum nasional yang relevan lainnya.

\section{KESIMPULAN}

Dari analisa dan uraian yang dilakukan pada bab pembahasan dapat disimpulkan hal-hal sebagai berikut:

1. Letak geografis Indonesia telah menjadikan Indonesia sebagai salah satu rute terpenting bagi perdagangan internasional lewat laut. Meskipun demikian, kondisi tersebut menjadikan perairan Indonesia sangat rentan akan berbagai ancaman kejahatan, terutama kejahatan transnational. Perairan Indonesia yang merupakan perairan yang paling berbahaya dimana paling sering terjadi berbagai ancaman maritim menyebabkan munculnya urgensi pengaturan keamanan maritim nasional. Meskipun kerjasama internasional dan regional penting dalam menghadapi ancaman maritime, instrumen hukum nasional yang baik akan mendukung implementasi kerjasama internasional dan regional yang ada.

2. Dari analisa di atas, hukum nasional Indonesia masih belum sesuai dengan ketentuan internasional serta hukum nasional yang ada juga sudah out of date. Dengan demikian pengaturan secara nasional tentang keamanan maritim sangat diperlukan, guna mengatasi ancaman maritim, kerangka hukum nasional yang komprehensif sangat diperlukan. 


\section{DAFTAR PUSTAKA}

Buku

Bjune, 2007, Catherine, Introduction to Maritime Law, Norwegia

D. Johnson, E. Pladder and M Valencia, J., 2005, "Introduction: Research on Southeast Asian Piracy" in D. Johnson, E. Pladdet and M Valencia, J. (eds), Piracy in Southeast Asia: Status, Issues, and Responses, ISEAS, Singapore

Hassan, David, 2006, Protecting the Marine Environment from Land-based Sources of Pollution: Towards Effective International Cooperation

H. Lowen and A. Boedenmuller, 2011, "'Straits of Malacca' in Stefan Mair (ed), Piracy and Maritime Security: Regional Characteristics and political, military, legal and economic implications, Stiftung Wissenschaft und Politik, Australia

Ibrahim, Jhony, 2006, Teori dan Metodologi Penelitian Hukum Normatif, Jakarta

Kimble, Melinda, 2007, 'Climate Change: Emerging Insecurities' in Felix Dodds and Tim Pippard (eds), Human and Environmental Security (2005) 103 -114. Asian Development Bank, A Regional Review of the Economics of Climate Change in Southeast Asia

Kusumaatmadja, Mochtar, Pengantar Hukum Internasional, Jakarta, 1999

Organisation for Economic Co-operation and Development, Fish Piracy: Combatting Illegal, Unreported and Unregulated Fishing, USA, (2004)

Schloenhardt, Andreas Migrant Smuggling: Illegal Migration and Organised Crime in Australia and the Asia Pacific Region, Melbourne, (2003)

Smith, Paul J, Terrorism and Violence in Southeast Asia: Transnational Challenges to States and Regional Stability, London, (2004)

Starke, J.G, Pengantar Hukum Internasional, Jakarta: Sinar Grafika, 1992

\section{Jurnal}

Barrios, Erik 'Casting a Wider Net: Addressing the Maritime Piracy Problem in Southeast Asia' (2005) 28 Boston College International and Comparative Law Review 149

Bateman, Sam 'Regional Responses to Enhance Mari- time Security in East Asia ' (2006) 18(2) Korean Journal of Defense Analysis 25

Barrios, Erick, 'Casting a Wider Net: Addressing the Maritime Piracy Problem in Southeast Asia' (2005) 28 Boston College International and Comparative Law Review 149

Bateman, Sam 'Assessing the Threat of Maritime Terrorism: Issues for the Asia-Pacific Region' (2006) 2 Security Challenges, 77

Bateman, Sam, 'Regional Responses to Enhance Maritime Security in East Asia ' (2006) 18(2) Korean Journal of Defense Analysis 25 at 28 -30.

Bautista, Lowell dan Puspitawati, Dhiana, International Legal Implications of Archipelagic State Status on Maritime Security in Souteast Asia (A Comparison between the Practice of Indonesia and the Philippines), Laporan Penelitian yang belum dipublikasikan, Fakultas Hukum Universitas Brawijaya, 2013

Beckman, Robert C, 'Combatting Piracy and Armed Robbery Against Ships in Southeast Asia: The Way Forward' (2002) 33 Ocean Development EF International Law 317

Buzan, Barry, Weaver, Ole and de Wilde, Jaap, Security: A New Framework for Analyses, Lynne Rienner Publisher, Colorado

Chalk, Peter 'Contemporary Maritime Piracy in Southeast Asia' (1998) 21 Studies in Conflict $\mathcal{E}$ Terrorism 87

Feldt, Ludtz, Roell, Peter and Thiele, Ralph D, 'Maritime Security - Perspectives for a Comprehensive Approach', ISPSW Strategy Series, n. 22, 2013.

Jon, Joon-Soo 'East Asian Shipping Ownership' in Andrew Forbes (ed), The Strategic Importance of Seaborn Trade and Shipping (2003), 61.

Keliat, Makmur, "Keamanan Maritim dan Implikasi Kebijakannya bagi Indonesia”, Jurnal Ilmu Sosial dan Ilmu Politik, v13, n1, Juli 2009

Kimble, Melinda 'Climate Change: Emerging Insecurities' in Felix Dodds and Tim Pippard (eds), Human and Environmental Security (2005) 103 -114. Asian Development Bank, A Regional Review of the Economics of Climate Change in Southeast Asia (2007), 1 - 2.

Lis Gindarsah and Adhi Priamarizki, 'Indonesia's Maritime Doctrine and Security Concerns', RSIS Publication, 2014, available at <https://www.rsis.edu.sg/ wp-content/.../PR150409_Indonesias-Maritime- 
Doctrine.pdf>, accessed 14 July 2016.

Lizee, Piere and Peou, Sorpong, 'Cooperative Security and the Emerging Security Agenda in Southeast Asia: The Challenges and Opportunities of Peace in Cambodia', YCISS Ocassional Paper No. 21, Toronto, Centre for International and Strategic Studies, York University, 1993.

Ong, Graham Gerard Piracy, Maritime Terrorism and Securing the Malacca Straits (2006)

Organisation for Economic Co-operation and Development, Fish Piracy: Combatting Illegal, Unreported and Unregulated Fishing (2004)

Puspitawati, Dhiana, "Hukum Laut atau Hukum Maritim?", Jawapos (Surabaya), 22 May 2006

Puspitawati, Dhiana, 'Coordinate Transnational Security over ASEAN Waters on $21^{\text {st }}$ Era', Paper presented at International Conference Harmonizing Legal Principles Toward Asean Community, Surabaya, 2nd - 4th April 2012, Joint Collaboration Utrecht University School of Law and Airlangga University Faculty of Law

Raymond, Catherine Zara 'Piracy in Southeast Asia: New Trends, Issues and Responses' (2005) 9 Harvard Asia Quarterly

Ruolngul, James R, 'Security, Politics and Regional Integration' on-line http://www.articlesbase.com/politicsarticles/security-politics-and-regional-integrationasean-mercosur-and-sadc-836206.html

Schloenhardt, Andreas Migrant Smuggling: Illegal Migration and Organised Crime in Australia and the Asia Pacific Region (2003).

Smith, Paul J. Terrorism and Violence in Southeast Asia: Transnational Challenges to States and Regional Stability (2004).

Soeharto, "Address by the President of the Republic of Indonesia”, Regionalism in Souteast Asia, Centre for Strategic and International Studies, 1975

The Present addendum to the Report of the SecretaryGeneral on Oceans and the Law of the Sea (A/63) 63)

Werner vom Busch and Tobias Rettig (eds), Covering Maritime Piracy in Southeast Asia (2006)

Wibawa, A.C., "Toward Indonesia's Global Maritime Fulcrum: Legal Analyses on Maritime Security Framework", Centre for Defence and Strategic Studies,
Australia, Unpublished paper, 2016.

Young, Adam J. Contemporary Maritime Piracy in Southeast Asia: History, Causes and Remedies (2007)

\section{Konvensi Internasional}

International Maritime Organization Convention 1948 United Nations Convention on the Law of the Sea 1982

International Convention on the Life at Sea 1974 (SOLAS 1974)

Guide to Australian Maritime Security Arrangement (GAMSA)

\section{Peraturan Perundang Undangan}

Undang-Undang No. 6 Tahun 1996 tentang Perairan Indonesia

Undang-Undang No. 17/2008 tentang Pelayaran Undang-Undang No. 45 Tahun 2009 tentang Perikanan Undang-Undang No 32 Tahun 2014 tentang Kelauatn Peraturan KSAL No. 32 tahun 2009 tentang Prosedur Tetap Penegakan Hukum dan Penjagaan Keamanan di Wilayah Laut Yurisdiksi Nasional oleh TNI-AL 